\title{
A new model for density of nanofluids including nanolayer
}

Mohsen Sharifpur*, Saboura Yousefi, Josua Petrus Meyer

Nanofluids Research Laboratory, Department of Mechanical and Aeronautical Engineering, University of Pretoria, Pretoria 0002, South Africa

\section{Abstract}

Nanofluids which are suspension of nanoparticles in conventional heat transfer fluids attracted researchers while they show higher thermal conductivity and specific heat capacity. The important parameters have influence on thermal-fluid properties of nanofluids include the volume fraction of the nanoparticles, temperature, density of fluid base and nanoparticles, nanoparticles size, nanolayer, thermal conductivity of base fluid and particles, and $\mathrm{pH}$. Nanolayer which is an approved interfacial layer between particles and base fluid involved in some of modelling for effective thermal conductivity and effective viscosity of nanofluids. Therefore, this layer must effect on other properties of nanofluids such as density. In this study investigation into the density of nanofluids has done experimentally. The nanofluids were investigated for density measurements consist of $\mathrm{SiO}_{2}-\mathrm{Water}, \mathrm{MgO}-$ Glycerol, CuO-Glycerol and SiOx-Ethylene Glycol /Water for range of 1 to $6 \%$ volume fraction as well as temperature range of 10 to $40^{\circ} \mathrm{C}$. The results show that mixture model for density of nanofluids (density of nanofluid = density of base fluid multiply by volume fraction of base fluid + density of nanoparticles multiply by volume fraction of nanoparticles) which is generally cited in literature has higher value than experimental data. For higher volume fraction of nanoparticles, the gap between the experimental results and the mixture model gets more. This is due to the nanolayer which also shows nanolayer density can be between void and the base fluid density. Therefore, based on the experimental data a new model for density of nanofluids developed which includes nanolayer. It was also found that the amount of the void in the nanolayer is more sensitive to nanoparticle size and not to base fluids or nanoparticles material.

\footnotetext{
*Author for correspondence E-mail: mohsen.sharifpur@up.ac.za Tel: +27 (0) 124202448

Fax: +27 (0) 124206632
} 
Key words: Nanolayer, nanofluids, density, $\mathrm{SiO}_{2}, \mathrm{MgO}$, SiOx, ethylene glycol, glycerol Nomenclature

$\begin{array}{ll}\text { EG } & \text { Ethylene Glycol } \\ \mathrm{m} & \text { Mass, gr } \\ n & \text { Approximate number of nanoparticles } \\ r & \text { Radius, } \mathrm{nm} \\ t & \text { Equivalent thickness, } \mathrm{nm} \\ \mathrm{V} & \text { Volume, } \mathrm{cm}^{3}\end{array}$

Greek symbols

$\begin{array}{ll}\rho & \text { Density, } \mathrm{kg} / \mathrm{m}^{3} \\ \varphi & \text { Volume fraction }\end{array}$

Subscript

$\begin{array}{ll}p & \text { Nanoparticle } \\ f & \text { Based fluids } \\ n f & \text { Nanofluids } \\ v & \text { Void }\end{array}$

1. Introduction

Thermal and physical properties of fluids play a vital role in developing heat transfer equipment with high efficiency. Conventional heat transfer fluids like water, engine oil, glycerol and ethylene glycol (EG) have limitations on heat transport. On the other hand rapid development of technology and generating enormous amount of heat in new heat transfer systems such as micro electromechanical machines and high efficiency heat exchangers require enhanced heat transfer fluids. The main factor in the efficiency of thermal transport of a heat transfer fluid is the thermal conductivity. However, conventional heat transfer fluids have poor thermal properties comparing with solids. A way to improve thermal conductivity of the conventional heat transfer fluids is to disperse solid particles into them. The idea of dispersing micrometer- or millimeter-sized solid particles in fluids can be traced back to Maxwell theoretical work in 1873 [1]. Numerous theoretical and 
experimental studies have been done to increase thermal conductivity properties of fluids by dispersing millimeter or micrometer sized particles in fluids. Although adding these solid particles may improve thermal conductivity of conventional heat transfer fluids, but they could cause clogging, wearing and significant pressure drop as well as stability and sedimentation problems. By using nano-meter size particles (nanoparticles), Choi [2] proposed employing nanofluids, which are solid-liquid composite materials including nanoparticles suspended in different heat transfer fluids (base fluids). Numerous studies have been done to evaluate nanofluids properties to introduce them into industrial design and applications. Volume fraction of the nanoparticles, temperature, nanoparticle size, nanolayer, thermal conductivity of the base fluid, $\mathrm{pH}$ of the nanofluid, and the thermal conductivity of the nanoparticles have been pointed out by several authors as important parameters effecting on properties of nanofluids $[1,3,4]$. Density of a nanofluid is one of the most important physical properties of the nanofluid (as a fluid) which has not been investigated deeply to date. Classical mixture density model (linear approach for densities and volume fractions) for conventional solid-liquid mixture has been used by almost all of the researchers [5-45] when calculating nanofluids' density, which has not considered nanolayer. However, nanolayer as a fact is an approved layer existing between a nanoparticle and the base fluid [1] in a nanofluid.

In this paper, it is investigated the density of four different nanofluids consist of $\mathrm{SiO}_{2}$-Water, MgO-Glycerol, SiOx-EG 60\% /Water40\% and CuO-Glycerol experimentally as well as the influences of nanolayer on nanofluid density to develop a new model. Experimental works have been done to measure density of the nanofluids accurately. The result of the experimental density measurements shows a gap between the experimental data and the mixture model approach. The gap increases by increasing the volume fraction of the nanoparticles which shows nanolayer plays a role. Therefore, a new model has been developed for calculation of nanofluids density including nanolayer.

\section{Solid-liquid interfacial layer}

Some theoretical analyses and molecular simulations have been done to investigate properties of liquids at solid-liquid interfaces. Probing structure of these interfaces was difficult and the theoretical analyses were not verified experimentally. Henderson and van 
Swol [46] analysed the properties of a fluid in presence of a hard wall. In their research, theoretical analysis has been done and the results of molecular dynamic simulation of hard sphere-fluid bounded by a pair of planar wall were used. They predicted density oscillation of molecules close to the solid liquid interface from the simulation results. They also discussed the presence of layering of fluid molecules in the interface of planar wall and fluid. Thompson and Robbins [47] worked on epitaxial order of fluid near solids. They showed the degree of slip on solid is directly related to wall-fluid interaction. They indicated that at large interactions substantial epitaxial ordering happens and the first or two fluid layers become locked to the wall. Huisman et al. [48] investigated structure of solid-liquid interface with a synchrotron X-ray diffraction method. The method can be effective because of deep penetration of $x$-rays in matter. The specular reflectivity was measured in Ga/Diamond (111)-2x1 interface. They reported exponentially decaying density oscillation in the $\mathrm{Ga} /$ Diamond interface. In their experiment, liquid gallium was super-cooled so the layering could be consequence of local freezing.

In 1998, Huisman and van der Veen [49] introduced a model for the density profile in the solid-liquid interface by measuring specular X-ray reflectivity of liquid Gallium around solid Diamond. They offered a model for interface structure of Gallium atoms closed to surface of Diamond, forming as solid like layer with high electron density.

Doerr et al. [50] studied thin liquid hexane films on silicon with specular and off-specular X-ray scattering. Their experimental results show one solid-liquid interfacial layer extended to $4 \mathrm{~nm}$ from the interface. They concluded that the ordering of an interfacial layer in solidliquid interface is independent of liquid film thickness. Yu et al. [51] studied interfacial properties of thin liquid film of TEHOS (tetrakis(2-ethylhexoxy)silane) on silicon (111) substrate by X-ray reflectivity. They showed that three electron density oscillations near the interface with a period of about $1 \mathrm{~nm}$, which is consistent with molecular density. In 2000, Yu et al. [52] studied interface layering of TEHOS as a normal liquid at room temperature which was higher than freezing point. Samples of various thicknesses had been tested and density oscillations of a period of $1 \mathrm{~nm}$ independent of film thicknesses reported. Yu et al. [53] used synchrotron X-rays to study solid-liquid interface of three different liquids on silicon substrates. They studied ultrathin (45-90 $\mathrm{A})$ and thick (5000 $\mathrm{A})$ liquid films and found 
that the liquid molecules are form 3-6 layers at the interface with plane close to molecular dimensions.

According to above mentioned studies there is no doubt in presence of liquid ordering in the solid-liquid interfaces. However, there are no certain models for predicting the interfacial layer properties.

\section{Experimental procedure and material}

The Rudolph DDM 2911 Laboratory Density Meter which is one of the most capable measuring instruments with the accuracy of $0.00005 \mathrm{gr} / \mathrm{cm}^{3}$ has been used to measure nanofluid density in the temperature range.

In these experiments, $\mathrm{SiO}_{2}, \mathrm{SiOx}, \mathrm{CuO}$ and $\mathrm{MgO}$ nanoparticles from Nanostructured \& Amorphous Materials Companies with particle size and density of $80 \mathrm{~nm}-2.40 \mathrm{gr} / \mathrm{cm}^{3}$, $20 \mathrm{~nm}-2.40 \mathrm{gr} / \mathrm{cm}^{3}, 40 \mathrm{~nm}-6.40 \mathrm{gr} / \mathrm{cm}^{3}$ and $40 \mathrm{~nm}-3.58 \mathrm{gr} / \mathrm{cm}^{3}$, respectively, have been used. Deionized water, glycerol and a 60:40 (in weight) EG-water mixture were used as base fluids to produce $\mathrm{SiO}_{2}$-Water, $\mathrm{MgO}-$-Glycerol, SiOx-EG60\%-Water40\% and CuO-Glycerol nanofluids. The deionized water, EG and glycerol were obtained from Merck South Africa Company, with density of $0.99704,1.115$ and $1.261 \mathrm{gr} / \mathrm{cm}^{3}$ at $25^{\circ} \mathrm{C}$, respectively.

Samples preparation were carried out using a very sensitive mass balance with $0.1 \mathrm{mg}$ readability and accuracy of $0.2 \mathrm{mg}$ and a dispenser with $0.01 \mathrm{ml}$ readability and accuracy of $0.005 \mathrm{ml}$. Nanoparticles were dispersed with different volume concentrations $(1 \%, 2 \%, 4 \%$, and 6\%) in the base fluids. The mixtures were stirred and agitated thoroughly, and by using ultrasonificator to find homogenous nanofluids. The nanofluids of $60 \mathrm{ml}$ were stirred and sonicated (40 kHz, 150W) continuously for 1 to 2 hours depending on the base fluid and volume fractions. During the sonifications, the temperature of the samples increases which may cause the evaporation of the base fluid, therefore, the samples were placed in a thermostatic constant temperature bath during sonication. All samples prepared before the density measurements and then each sample was measured by DDM 2911 Digital Density Meter. The density meter was calibrated with air and deionized water according to the user manual before starting nanofluids' density measurements. The density meter set to measure the samples for $10,20,30$ and $40^{\circ} \mathrm{C}$. The tube inside the density meter was washed 
by deionized water and acetone after completion of each sample measurement and dried by an air pump which was assembled inside the density meter.

4. Model development, results and discussion

Four different kinds of nanofluids were used for density measurement as $\mathrm{SiO}_{2}$-Water, SiOx-EG/ Water, CuO-Glycerol and MgO-Glycerol. These nanofluids were chosen while they show more stability (without using surfactant) concerning the previous achievements in this laboratory [58-61]. However, the density measurements have taken after the nanofluids preparation. The results of density measurements show deviation from classical formula (mixture model) equation (1) for solid-liquid mixtures which has been used for density calculation by different authors [5-45]. In this research, all the experimental measurements for the nanofluids densities were less than the value calculated by mixture model of equation (1). As it is clear in the mixture model, the nanolayer effect has not been considered in nanofluid density which could result these deviations.

$$
\rho_{n f_{-} o l d}=\varphi \rho_{p}+(1-\varphi) \rho_{f}
$$

To develop a model to explain the experimental measurements for nanofluid density, here is considered the volume of the void which involving the nanolayer as $V_{v}$, therefore, the density of the resultant nanofluid can be as:

$$
\rho_{n f \_n e w}=\frac{m_{p}+m_{f}}{V_{p}+V_{f}+V_{v}}
$$

where $m_{p}, m_{f}, V_{p}$ and $V_{f}$ are the mass of nanoparticles, the mass of base fluid, the volume of nanoparticles and the volume of base fluid, respectively. For spherical nanoparticles the volume of $n$ nanoparticle with average radius of $r_{p}$ can be calculated as:

$$
V_{p}=n\left(\frac{4}{3} \pi r_{p}^{3}\right)
$$

As the first assumption, let's consider the nanolayer is pure void to find which thickness can be exist for different experimental cases to response the gap between the experimental and mixture model, therefore, the volume of $n$ nanoparticles with nanolayer thickness of $t_{v}$ can be calculated as: 


$$
V_{p}+V_{v}=n\left(\frac{4}{3} \pi\left(r_{p}+t_{v}\right)^{3}\right)
$$

By substituting $n$ from equation (3) into equation (4), and then into equation 2, nanolayer thickness for each sample can be calculated by using the experimental data and equation (5)

$$
\rho_{n f_{-} \text {new }}=\frac{m_{p}+m_{f}}{V_{f}+V_{p}\left(r_{p}+t_{v}\right)^{3} / r_{p}{ }^{3}}
$$

From the average of all experimental data for each sample, the thickness of nanolayer as equivalent to pure void found as: $0.305 \mathrm{~nm}$ for $\mathrm{SiO}_{x}-\mathrm{EG} /$ Water ( $\mathrm{SiO}_{x}$ size $20 \mathrm{~nm}$ ), $0.710 \mathrm{~nm}$ for CuO-Glycerol (CuO size 40nm), $0.675 \mathrm{~nm}$ for MgO-Glycerol (MgO size 40nm), and $1.305 \mathrm{~nm}$ for $\mathrm{SiO}_{2}$-Water $\left(\mathrm{SiO}_{2}\right.$ size $\left.80 \mathrm{~nm}\right)$. This is consistent with some researchers [54-57] which considered the thickness of nanolayer between 1 and $3 \mathrm{~nm}$. However, previous research on the solid-liquid interface [51-53] showed that the nanolayer consist of different layer at the interface of the solid-liquid which can conclude that the property of nanolayer should be started from void to the base fluid. In this way the average thickness of the nanolayer of the nanofluids must be more than the $t_{v}$. However, equation (5) remains correct while the same amount of void should be involved in the nanolayer. From the value of $t_{v}$ for CuO-Glycerol (0.710) $\mathrm{nm}, \mathrm{MgO}-$ Glycerol $(0.675 \mathrm{~nm})$ which both are $40 \mathrm{~nm}$ as well as the value for $20 \mathrm{~nm}$ and $80 \mathrm{~nm}$ sizes particles, can conclude that the value of $t_{v}$ could be more sensitive to the size of the particle, and therefore, $t_{v}$ can be considered equal to $0.305,0.695$ and 1.305 for $20 \mathrm{~nm}, 40 \mathrm{~nm}$ and $80 \mathrm{~nm}$ sizes, respectively. In this way, it can find the $t_{v}$ function of particle size approximately as

$$
t_{v}=-0.0002833 r_{p}^{2}+0.0475 r_{p}-0.1417
$$

With the same analogy (finding equation (5)) can find a new relation for resultant volume fraction when void involves in the nanolayer as

$$
\varphi_{\text {new }}=\frac{V_{p}}{V_{n f}}=\frac{V_{p}}{V_{p}+V_{f}+V_{v}}
$$

and finally: 


$$
\varphi_{\text {new }}=\frac{V_{p}}{V_{f}+V_{p}\left(r_{p}+t_{v}\right)^{3} / r_{p}{ }^{3}}
$$

or

$$
\varphi_{\text {new }}=\frac{m_{p} / \rho_{p}}{\left(m_{f} / \rho_{f}\right)+\left(m_{p} / \rho_{p}\right)\left(r_{p}+t_{v}\right)^{3} / r_{p}{ }^{3}}
$$

Equation (9) shows the actual volume fraction is a bit less than the conventional volume fraction and this equation can be utilized to find the volume fraction for experimental calculations accurately.

Equation (7) can be written in the following form as well:

$$
\varphi_{\text {new }}=\frac{V_{p}}{V_{n f}}=\frac{1}{\frac{1}{\varphi}-1+\left(r_{p}+t_{v}\right)^{3} / r_{p}^{3}}
$$

where $\varphi=V_{p} /\left(V_{p}+V_{f}\right)$, is the volume fraction without considering the nanolayer.

Concerning equation (10) the volume fractions of the samples in this research are listed in the table 1

In the same way, the equation (5) can be written in the form of equation (10) as

$$
\rho_{n f_{-} \text {new }}=\frac{\rho_{n f}}{(1-\varphi)+\varphi\left(r_{p}+t_{v}\right)^{3} / r_{p}^{3}}
$$

Equation (11) takes into consideration nanoparticles and base fluid densities, nanoparticle size, nanoparticle volume fraction and nanolayer. The approximation for $t_{v}$ is also given by equation (6).

The reliability of experimental results is examined by performing a relative uncertainty analysis [62]. The mean source of error could be the measurement of mass of nanoparticles, volume of the base fluid and the error of the density meter. Therefore, relative uncertainty found in rang of 0.012 to $0.016 \%$.

The comparison between experimental measurements and the new model (equation (11)) as well as mixture model has offered in the figures 1 to 4 for volume fraction range of 1 to $6 \%$ and temperature range of 10 to $40{ }^{\circ} \mathrm{C}$. Figure 1 consists of $\mathrm{SiO}_{2}$-Water nanofluids which shows the mixture model overestimated the experimental measurements as well as 
the new model agreed with the measurements. Figures 2 to 4 are for the cases of CuOGlycerol, MgO-Glycerol and $\mathrm{SiO}_{\mathrm{x}}-\mathrm{EG} 60 \%$-Water40\%. From the comparison of figures 1 to 4 can recognise that the new model of equation (11) works better than the mixture model, however, $t_{v}$ in the model correlated as function of particle diameter, and it needs future investigation to find more accurate correlation for $t_{v}$. It is also found that the gap between experimental data and the mixture model is less when the density of particle is more than the others in comparison to the base fluid. It can also indicate that the mixture model still works for volume fraction equal or less than $1 \%$.

\section{Conclusion}

In the present study, nanofluids density for $\mathrm{SiO}_{2}-$ Water, $\mathrm{MgO}-\mathrm{Glycerol}, \mathrm{CuO}-\mathrm{Glycerol}, \mathrm{SiO}_{x^{-}}$ EG60\%-Water40\% were measured experimentally for volume fractions of 1 to $6 \%$ and temperature range of 10 to $40^{\circ} \mathrm{C}$. The results show that the usual approach (mixture model) for nanofluids density offers overestimation, and the gap increases by increasing the volume fraction. This gap shows the nanolayer must be considered for density predictions as well as the nanolayer involves void. Therefore, from all experimental results the average of the equivalent void thickness in the nanolayer calculated and found it is more sensitive to particle size than the other parameters (material of the nanoparticles or base fluid). Consequently, in the present work a new model for nanofluids density has proposed includes the equivalent void thickness of the nanolayer. The comparison of the new model and experimental data shows good agreement in comparison to mixture model. However, the mixture model still works for volume fraction equal or less than $1 \%$.

\section{Acknowledgment:}

The Authors duly acknowledge and appreciate the funding obtained from National Research Foundation of South Africa (NRF) and EIRT-seed. The authors would also like to thank Ms Annette Venter, Department of Paraclinical Sciences, Faculty of Veterinary Science, University of Pretoria for making the densitometer available for this study and for kind technical assistance. 
References:

[1] Hikmet Ş. Aybar, Mohsen Sharifpur, M. Reza Azizian, Mehdi Mehrabi, and Josua P. Meyer, A Review of Thermal Conductivity Models of Nanofluids, Heat Transfer Engineering, Vol. 36 (13) pp. 1085-1110, 2015S. Choi, “Enhancing thermal conductivity of fluids with nanoparticles," Development and Applications of NonNewtonian Flows, pp. 99-105, 1995.

[2] S. Choi, "Enhancing thermal conductivity of fluids with nanoparticles," Development and Applications of Non-Newtonian Flows, pp. 99-105, 1995.

[3] M. Sharifpur and T. Ntumba, "Parametric analysis of effective thermal conductivity models for nanofluids," in Proceedings of the ASME 2012 International Mechanical Engineering Congress and ExpositionASME 2012 International Me, Houston, 2012.

[4] J. Meyer, P. Nwosu, M. Sharifpur and T. Ntumba, "Parametric analysis of effective viscosity models for nanofluids," in Proceedings of the the ASME 2012 International Mechanical Engineering Congress \& Exposition, Houston, 2012.

[5] I. Behroyan, Sh.M. Vanaki, P. Ganesan, R. Saidur, A comprehensive comparison of various CFD models for convective heat transfer of $\mathrm{Al} 2 \mathrm{O} 3$ nanofluid inside a heated tube, International Communications in Heat and Mass Transfer 70 (2016) 27-37.

[6] Sh.M. Vanaki , H.A. Mohammed, Numerical study of nanofluid forced convection flow in channels using different shaped transverse ribs, International Communications in Heat and Mass Transfer 67 (2015) 176-188.

[7] Fatih Selimefendigil, Hakan F. Öztop, Nidal Abu-Hamdeh, Mixed convection due to rotating cylinder in an internally heated and flexible walled cavity filled with SiO2water nanofluids: Effect of nanoparticle shape, International Communications in Heat and Mass Transfer 71 (2016) 9-19.

[8] Yue-Tzu Yang, Hsiang-Wen Tang, Bo-Yan Zeng, Chao-Han Wu, Numerical simulation and optimization of turbulent nanofluids in a three-dimensional rectangular ribgrooved channel, International Communications in Heat and Mass Transfer 66 (2015) 71-79.

[9] Bin Sun, Wei Lei, Di Yang, Flow and convective heat transfer characteristics of Fe2O3- 
water nanofluids inside copper tubes, International Communications in Heat and Mass Transfer 64 (2015) 21-28.

[10] B.H. Salman, H.A. Mohammed, A.Sh. Kherbeet, Numerical and experimental investigation of heat transfer enhancement in a microtube using nanofluids, International Communications in Heat and Mass Transfer 59 (2014) 88-100.

[11] Xiangyin Meng and Yan Li, "Numerical study of natural convection in a horizontal cylinder filled with water-based alumina nanofluid", Nanoscale Res Lett. 2015; 10 : 142.

[12] M. Mohammadpourfard, H. Aminfar, M. Karimi, Numerical investigation of nonuniform transverse magnetic field effects on the swirling flow boiling of magnetic nanofluid in annuli, International Communications in Heat and Mass Transfer 75 (2016) 240-252.

[13] Unal Akdag, Selma Akcay, Dogan Demiral, Heat transfer enhancement with laminar pulsating nanofluid flow in a wavy channel, International Communications in Heat and Mass Transfer 59 (2014) 17-23.

[14] Nor Azizah Yacob, Anuar Ishak, loan Pop, and Kuppalapalle Vajravelu, "Boundary layer flow past a stretching/shrinking surface beneath an external uniform shear flow with a convective surface boundary condition in a nanofluid", Nanoscale Res Lett. $2011 ; 6(1): 314$.

[15] Mostafa Keshavarz Moraveji, Reza Mohammadi Ardehali, CFD modeling (comparing single and two-phase approaches) on thermal performance of Al203/water nanofluid in mini-channel heat sink, International Communications in Heat and Mass Transfer 44 (2013) 157-164.

[16] Hang Xu, Tao Fan, loan Pop, Analysis of mixed convection flow of a nanofluid in a vertical channel with the Buongiorno mathematical model, International Communications in Heat and Mass Transfer 44 (2013) 15-22.

[17] M. Parsazadeh, H.A. Mohammed, F. Fathinia, Influence of nanofluid on turbulent forced convective flow in a channel with detached rib-arrays, International Communications in Heat and Mass Transfer 46 (2013) 97-105. 
[18] M. Sheikholeslami, M. Gorji-Bandpay, D.D. Ganji, Magnetic field effects on natural convection around a horizontal circular cylinder inside a square enclosure filled with nanofluid, International Communications in Heat and Mass Transfer 39 (2012) 978986.

[19] M.H. Kayhani , H. Soltanzadeh, M.M. Heyhat, M. Nazari, F. Kowsary, Experimental study of convective heat transfer and pressure drop of TiO2/water nanofluid, International Communications in Heat and Mass Transfer 39 (2012) 456-462.

[20] A.M. Rashad, M.M. Rashidi, G. Lorenzini, S. E. Ahmed, A.M. Aly, Magnetic field and internal heat generation effects on the free convection in a rectangular cavity filled with a porous medium saturated with $\mathrm{Cu}$-water nanofluid, Int. J. Heat Mass Transf. $2017,878-889$.

[21] K.Y. Leong, R. Saidur, M. Khairulmaini, Z. Michael, A. Kamyar, Heat transfer and entropy analysis of three different types of heat exchangers operated with nanofluids, International Communications in Heat and Mass Transfer 39 (2012) 838843.

[22] Mahmoud Reza Khadangi Mahrood, Seyed Gholamreza Etemad, Rouhollah Bagheri, Free convection heat transfer of non Newtonian nanofluids under constant heat flux condition, International Communications in Heat and Mass Transfer 38 (2011) 14491454.

[23] Mina Shahi, Amir Houshang Mahmoudi, Farhad Talebi, Numerical simulation of steady natural convection heat transfer in a 3-dimensional single-ended tube subjected to a nanofluid, International Communications in Heat and Mass Transfer 37 (2010) 1535-1545.

[24] O. Ghaffari, A. Behzadmehr, H. Ajam, Turbulent mixed convection of a nanofluid in a horizontal curved tube using a two-phase approach, International Communications in Heat and Mass Transfer 37 (2010) 1551-1558.

[25] Oronzio Manca, Paolo Mesolella, Sergio Nardini, and Daniele Ricci, "Numerical study of a confined slot impinging jet with nanofluids", Nanoscale Res Lett. 2011; 6(1): 188.

[26] M. Rostamani, S.F. Hosseinizadeh, M. Gorji, J.M. Khodadadi, Numerical study of 
turbulent forced convection flow of nanofluids in a long horizontal duct considering variable properties, International Communications in Heat and Mass Transfer 37 (2010) 1426-1431.

[27] E. Buyuk Ogut, "Natural convection of water-based nanofluids in an inclined enclosure with a heat source," International Journal of Thermal Sciences, p. 20632073, 2009.

[28] S. Kumar, S. Kumar Prasad, and J. Banerjee, "Analysis of flow and thermal field in nanofluid using a single phase thermal dispersion model," Applied Mathematical Modelling, p. 573-592, 2010.

[29] Z. Alloui, J. Guiet, P. Vasseur and M. Reggi, "Natural convection of nanofluids in a shallow rectangular enclosure heated from the side," The Canadian Journal of Chemical Engineering, pp. 69-78, 2012.

[30] V. Kuppalapalle, "The effect of variable viscosity on the flow and heat transfer of a viscous Ag- water and Cu-water nanofluids," Journal of Hydrodynamics, pp. 1-9, 2013.

[31] I. I. Ryzhkov and A. V. Minakov, "The effect of nanoparticle diffusion and thermophoresis on convective heat transfer of nanofluid in a circular tube," International Journal of Heat and Mass Transfer, p. 956-969, 2014.

[32] A. A. Minea, "Uncertainties in modeling thermal conductivity of laminar forced convection heat transfer with water alumina nanofluids," International Journal of Heat and Mass Transfer, pp. 78-84, 2014.

[33] Omidreza Sadeghi, H.A. Mohammed, Marjan Bakhtiari-Nejad, M.A.Wahid, Heat transfer and nanofluid flow characteristics through a circular tube fitted with helical tape inserts, International Communications in Heat and Mass Transfer 71 (2016) 234244.

[34] S. S. Azimi and M. Kalbasi, "Numerical study of dynamic thermal conductivity of nanofluid in the forced convective heat transfer," Applied Mathematical Modelling, p. 1373-1384, 2014.

[35] A. inakov, A. Lobasov, D. Guzei, M. Pryazhnikov and V. Ya Rudyak, "The experimental and theoretical study of laminar forced convection of nanofluids in the round 
channel," Applied Thermal Engineering, pp. 1-9, 2014.

[36] Hussein Togun, H.I. Abu-Mulaweh, S.N. Kazi, A. Badarudin, Numerical simulation of heat transfer and separation Al203/nanofluid flow in concentric annular pipe, International Communications in Heat and Mass Transfer 71 (2016) 108-117.

[37] C. Cianfrini, M. Corcione, E. Habib and A. Quintino, "Buoyancy-induced convection in Al203/water nanofluids from an enclosed heater," European Journal of Mechanics B/Fluids, pp. 123-134, 2014.

[38] M. Hemmat Esfe, S. Saedodin and M. Mahmoodi, "Experimental studies on the convective heat transfer performanceand thermophysical properties of $\mathrm{MgO}$-water nanofluid under turbulent flow," Experimental Thermal and Fluid Science, pp. 68-78, 2014.

[39] Hadi Ghodsinezhad, Mohsen Sharifpur, Josua Petrus Meyer, Experimental investigation on cavity flow natural convection of Al2O3-water nanofluids, International Communications in Heat and Mass Transfer 76 (2016), 316-324.

[40] Wei-Ching Chen,Wen-Tung Cheng, Numerical simulation on forced convective heat transfer of titanium dioxide/water nanofluid in the cooling stave of blast furnace, International Communications in Heat and Mass Transfer 71 (2016) 208-215.

[41] H. Maddah, M. Alizadeh, N. Ghasemi and S. Rafidah Wan Alwi, "Experimental study of Al2O3/water nanofluid turbulent heat transfer enhancement in the horizontal double pipes fitted with modified twisted tapes," International Journal of Heat and Mass Transfer, p. 1042-1054, 2014.

[42] C. Pang, J. Won Lee and Y. Tae Kan, "Review on combined heat and mass transfer characteristics in nanofluids," International Journal of Thermal Sciences, pp. 49-67, 2015.

[43] A. M. Abed, M. Alghoul, K. Sopian, H. Mohammed, H. s. Majdi and A. N. Al-Shamani, "Design characteristics of corrugated trapezoidal plate heat exchangers using nanofluids," Chemical Engineering and Processing, p. 88-103, 2015.

[44] Gabriela Huminic, Angel Huminic, Heat transfer and entropy generation analyses of nanofluids in helically coiled tube-in-tube heat exchangers, International 
Communications in Heat and Mass Transfer 71 (2016) 118-125.

[45] A. Najah Al-Shamani, K. Sopian, H. Mohammed, S. Mat, M. Hafidz Ruslan and A. M. Abed, "Enhancement heat transfer characteristics in the channel with Trapezoidal rib-groove using nanofluids," Case Studies in Thermal Engineering, pp. 48-58, 2015.

[46] J. R. Henderson and F. van Swol, "On the interface between a fluid and a planar wall Theory and simulations of a hard sphere fluid at a hard wall," Molecular Physics, pp. 991-1010, 1984.

[47] P. A. Thompson and M. O. Robbins, "Shear flow near solids: Epitaxial order and flow boundary conditions," Physical Review A, pp. 6830-6837, 1990.

[48] W. J. Huisman, J. F. Peters, J. W. Derks, D. L. Abernathy and J. F. van der Veen, "A new $x$-ray diffraction method for structural investigations of solid-liquid Interfaces," Rev. Sci. Instrum. 68 (11), pp. 4169-4176, 1997.

[49] W. J. Huisman and J. F. van der Veen, "Modelling the atomic density across a solidliquid interface," Surface Science, p. 866-870, 1998.

[50] A. Doerr, M. Tolan, T. Seydel and W. Press, "The interface structure of thin liquid hexane films," Physica B, pp. 263-268, 1998.

[51] C.-J. Yu, A. G. Richter, A. Datta, M. K. Durbin and P. Dutta, “Observation of Molecular Layering in Thin Liquid Films Using X-Ray Reflectivity_66," Phyisical Review Letters, pp. 2326-2329, 1999.

[52] C.-J. Yu, A. Richter, A. Datta, M. Durbin and P. Dutta, "Molecular layering in a liquid on a solid substrate an X-ray reflectivity study," Physica B, pp. 31-16, 2000.

[53] C.-J. Yu, A. G. Richter, J. Kmetko, S. W. Dugan, A. Datta and P. Dutta, "Structure of interfacial liquids: X-ray scattering studies," PHYSICAL REVIEW E, VOLUME 63, 021205, pp. 021205-1 - 021205-2, 2001.

[54] W. Yu and S. Choi, "The role of interfacial layers in the enhanced thermal conductivity of nanofluids A renovated Maxwell mode," Journal of Nanoparticle Research, p. 167171, 2003.

[55] H. Xie, M. Fujii and X. Zhang, "Effect of interfacial nanolayer on the effective thermal," 
International Journal of Heat and Mass Transfer, p. 2926-2932, 2005.

[56] Q. Xue and W.-M. Xu, "A model of thermal conductivity of nanofluids with interfacial shells," Materials Chemistry and Physics, p. 298-301, 2005.

[57] R. Yajie, H. Xie and A. Cai, "Effective thermal conductivity of nanofluids containing spherical nanoparticles," J. Phys. D Appl. Phys., p. 3958-3961, 2005.

[58] Ntumba Tshimanga, Mohsen Sharifpur, Josua P. Meyer, Experimental Investigation and Model Development for Thermal Conductivity of Glycerol-MgO Nanofluids, Heat Transfer Engineering, Vol. 37, Issue 12, pp. 1-16, 2016.

[59] SA Adio, M Sharifpur and JP Meyer, "Influence of ultrasonication energy on the dispersion consistency of Al2O3-glycerol nanofluid based on viscosity data, and model development for the required ultrasonication energy density, Journal of Experimental Nanoscience Vol. 11, Issue 8, 630-649, 2016.

[60] Tshimanga Ntumba, M. Sharifpur and J.P. Meyer, The effective of sonication energy and time on thermal conductivity of Glycerol base nanofluids, Proceedings of the 15th International Heat Transfer Conference (IHTC-15), August 10-15, 2014, Kyoto, Japan.

[61] Hadi Ghodsinezhad, M. Sharifpur, J.P. Meyer, and Heidi Rolfes., Investigation on Ultrasonicaton Energy Density Effect on Size Distribution of Zinc Oxide (ZnO) Nanoparticles by Using Zeta-Sizer, Proceedings of the 11th International Conference on Heat Transfer, Fluid Mechanics and Thermodynamics (HEFAT 2015), July 20-23, 2015, Kruger National Park, South Africa.

[62] R. J. Moffat, "Describing the Uncertainties in Experimental Results," Experimental Thermal and Fluid Science, vol. 1, pp. 3-17, 1988. 
Table 1. Volume fractions of the samples with and without considering nanolayer

Table 1. Volume fractions of the samples with and without considering nanolayer

\begin{tabular}{|c|c|c|c|}
\hline Nanofluid & Particle size & $\begin{array}{c}\text { Volume fractions } \\
\text { Without nanolayer } \\
\text { (\%) }\end{array}$ & $\begin{array}{l}\text { Volume fractions } \\
\text { With nanolayer } \\
\text { Equation (10) } \\
\text { (\%) }\end{array}$ \\
\hline \multirow{4}{*}{ SiOx-EG/Water } & \multirow{4}{*}{$20 \mathrm{~nm}$} & 1 & 0.9991 \\
\hline & & 2 & 1.996 \\
\hline & & 4 & 3.985 \\
\hline & & 6 & 5.966 \\
\hline \multirow{4}{*}{$\begin{array}{l}\text { CuO-Glycerol } \\
\text { and } \\
\text { MgO-Glycerol }\end{array}$} & \multirow{4}{*}{$40 \mathrm{~nm}$} & 1 & 0.9989 \\
\hline & & 2 & 1.996 \\
\hline & & 4 & 3.983 \\
\hline & & 6 & 5.961 \\
\hline \multirow{4}{*}{$\mathrm{SiO}_{2}$-Water } & \multirow{4}{*}{$80 \mathrm{~nm}$} & 1 & 0.999 \\
\hline & & 2 & 1.996 \\
\hline & & 4 & 3.984 \\
\hline & & 6 & 5.964 \\
\hline
\end{tabular}




\section{Figures caption}

Fig. 1 Comparision of experimental results for density of $\mathrm{SiO}_{2}$-Water nanofluids with mixture model and new model $\mathrm{A}$ ) at $10^{\circ} \mathrm{C} \mathrm{B}$ ) at $20^{\circ} \mathrm{C}$ C) at $30^{\circ} \mathrm{C}$ ) at $40^{\circ} \mathrm{C}$.

Fig. 2 Comparision of experimental results for density of CuO-Glycerol nanofluids with mixture model and new model $\mathrm{A}$ ) at $10^{\circ} \mathrm{C} \mathrm{B}$ ) at $20^{\circ} \mathrm{C} \mathrm{C}$ ) at $30^{\circ} \mathrm{C} \mathrm{D}$ ) at $40^{\circ} \mathrm{C}$.

Fig. 3 Comparision of experimental results for density of MgO-Glycerol nanofluids with mixture model and new model $\mathrm{A}$ ) at $10^{\circ} \mathrm{C} \mathrm{B}$ ) at $20^{\circ} \mathrm{C}$ C) at $30^{\circ} \mathrm{C} \mathrm{D}$ ) at $40^{\circ} \mathrm{C}$.

Fig. 4 Comparision of experimental results for density of SiOx-EG/Water nanofluids with mixture model and new model $\mathrm{A}$ ) at $10^{\circ} \mathrm{C} \mathrm{B}$ ) at $20^{\circ} \mathrm{C}$ C) at $30^{\circ} \mathrm{C} \mathrm{D}$ ) at $40^{\circ} \mathrm{C}$. 


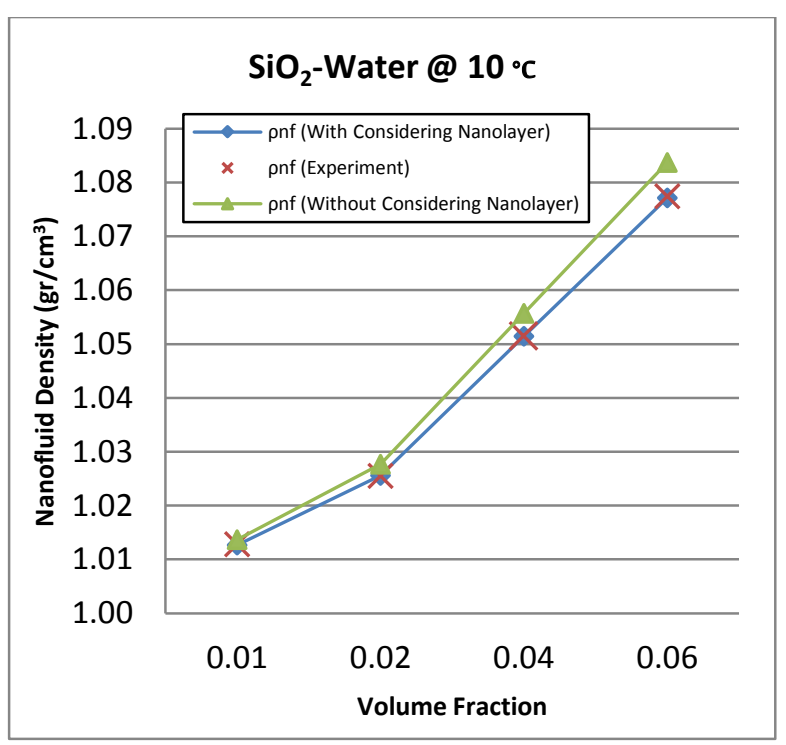

(A)

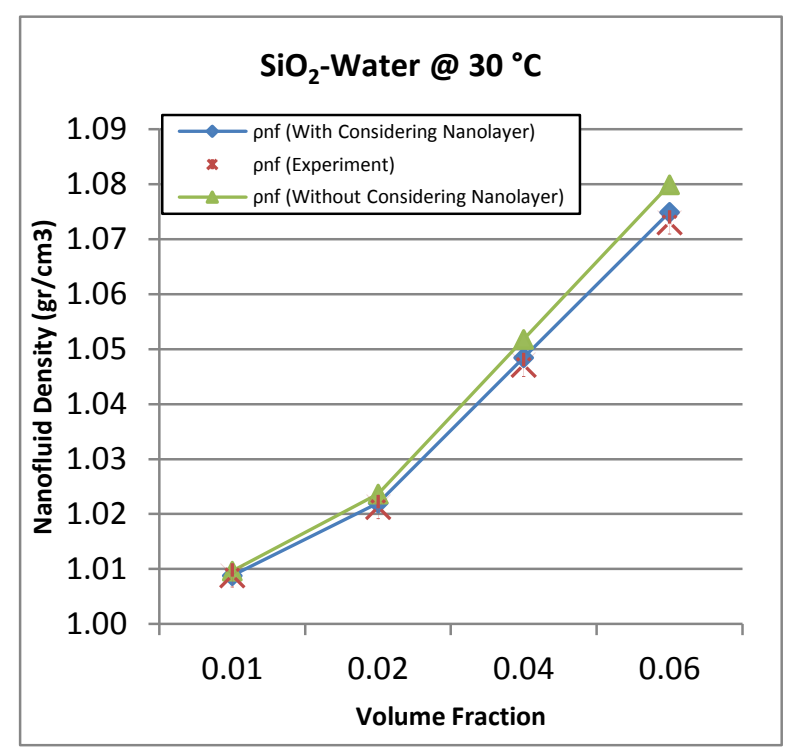

(C)

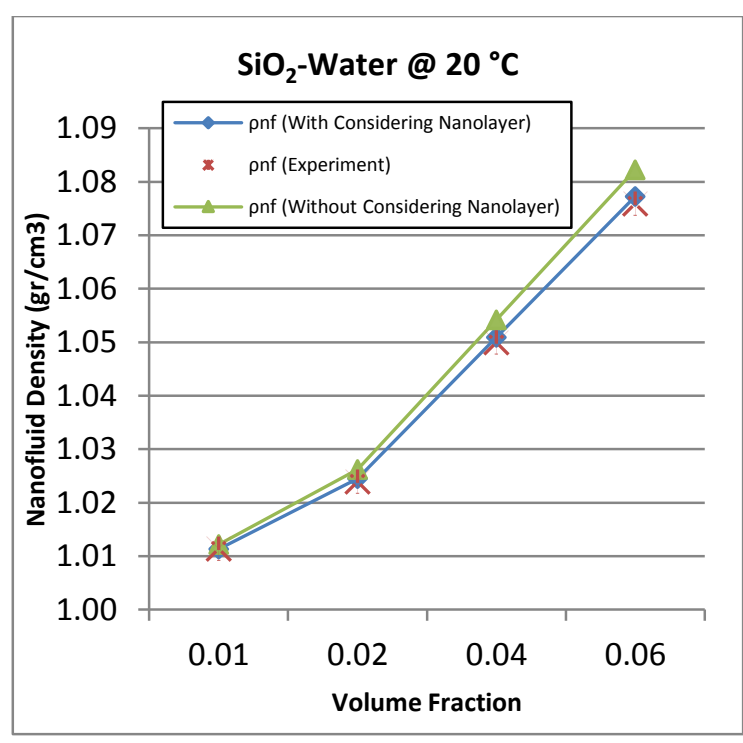

(B)

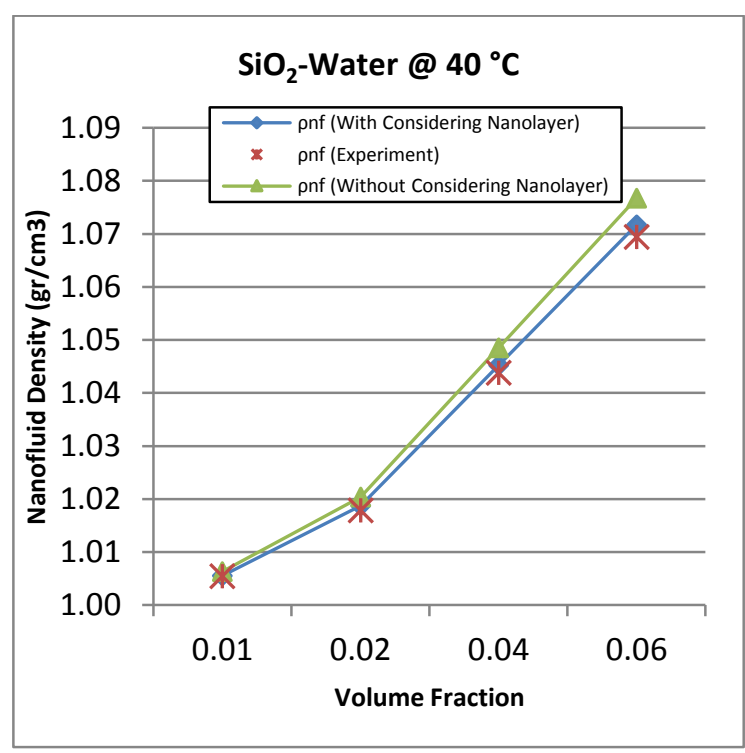

(D)

Fig. 1 


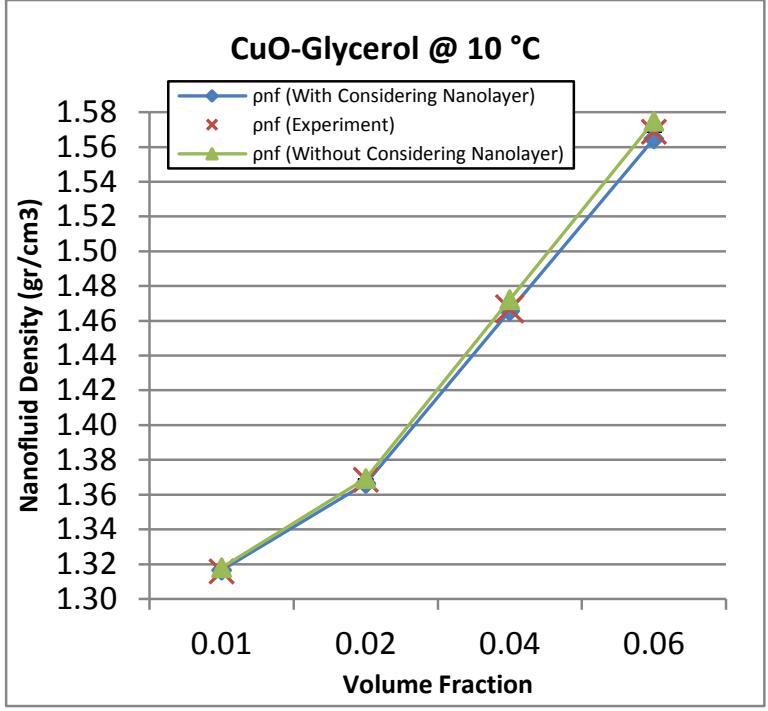

(A)

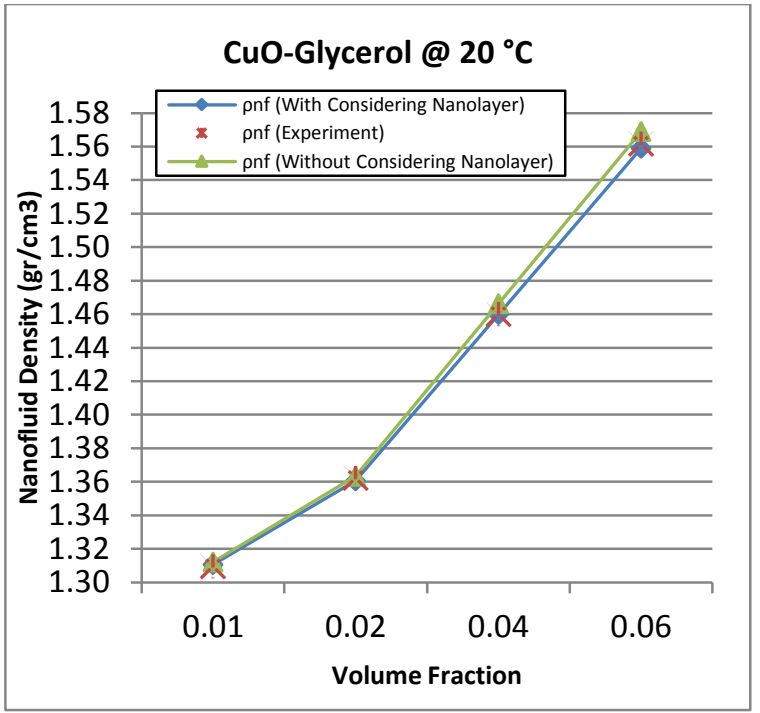

(B)

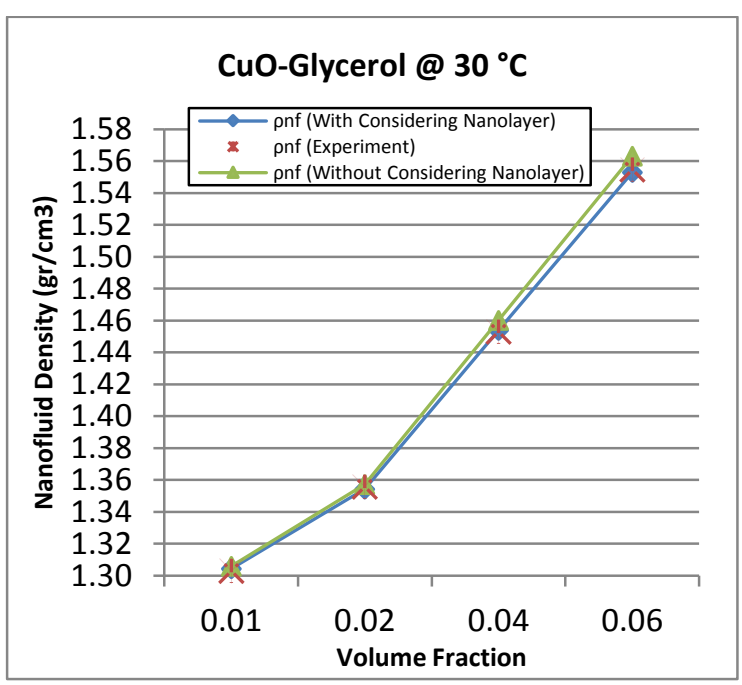

(C)

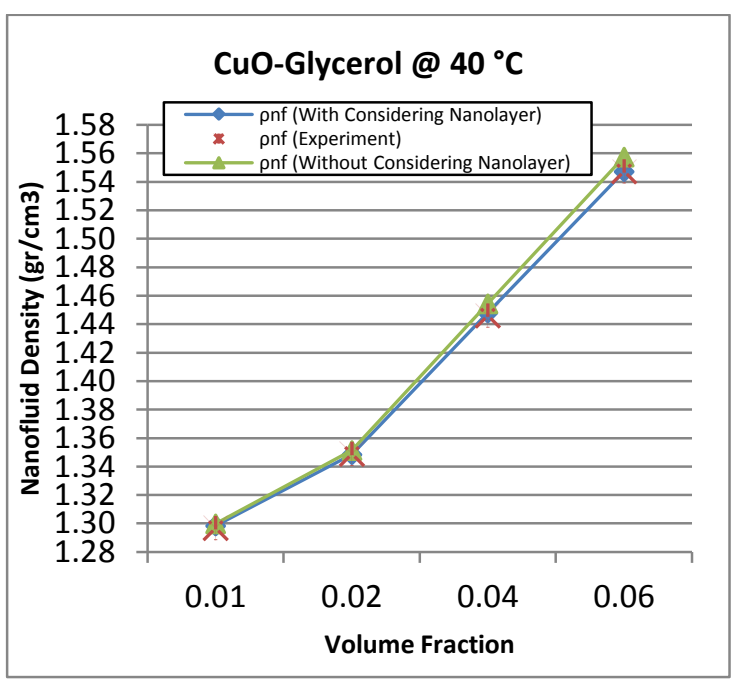

(D)

Fig. 2 


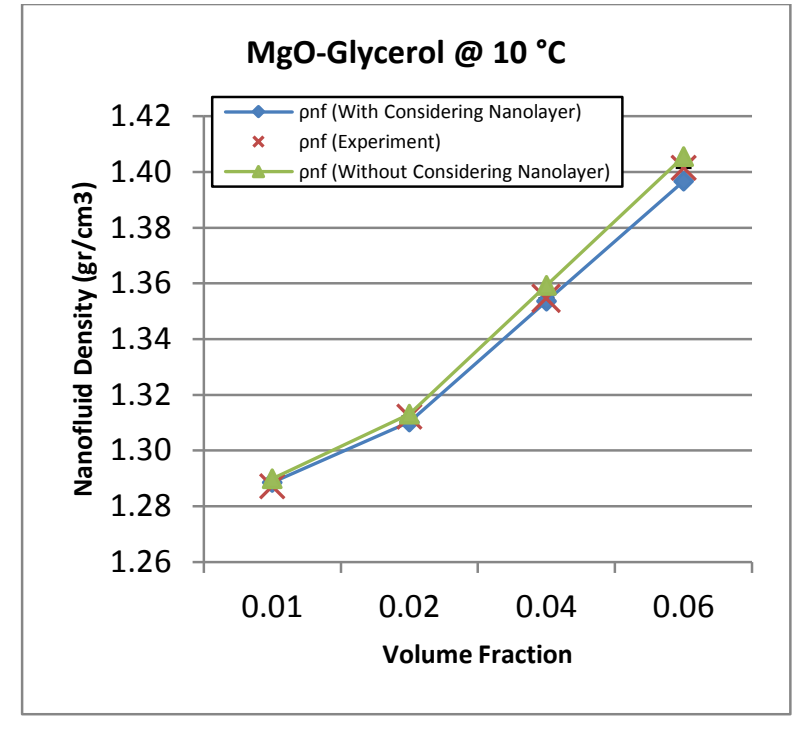

(A)

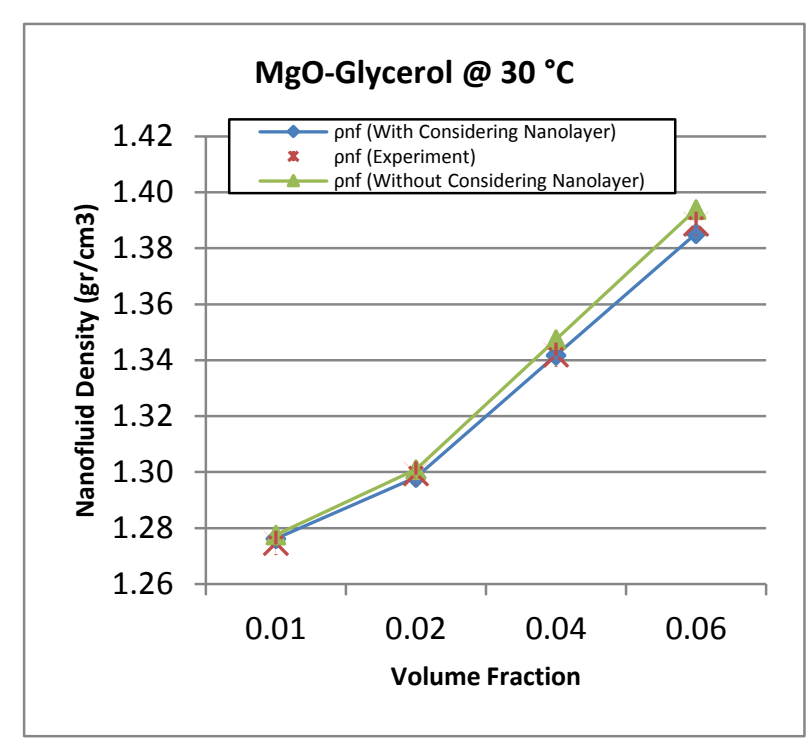

(C)

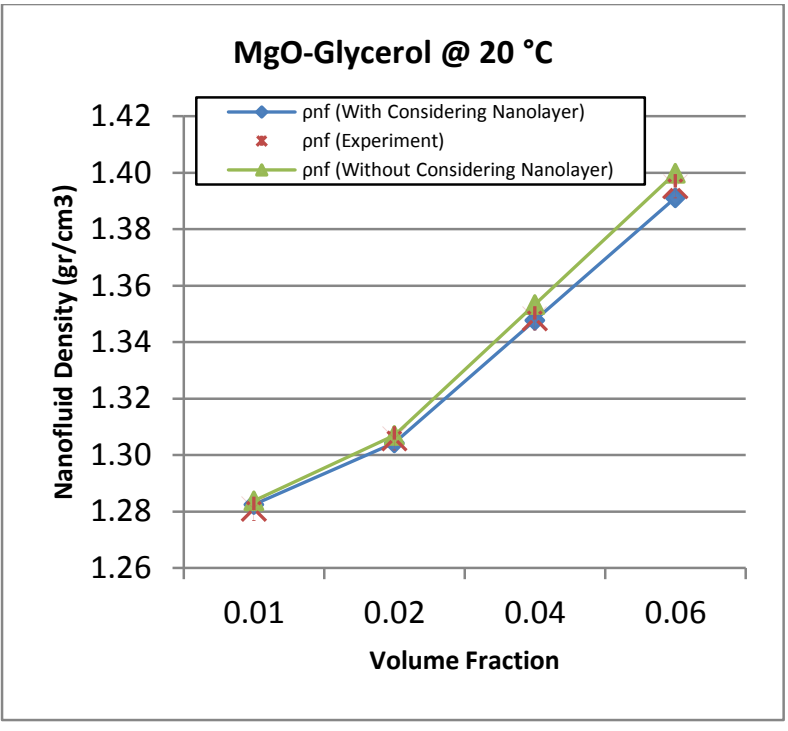

(B)

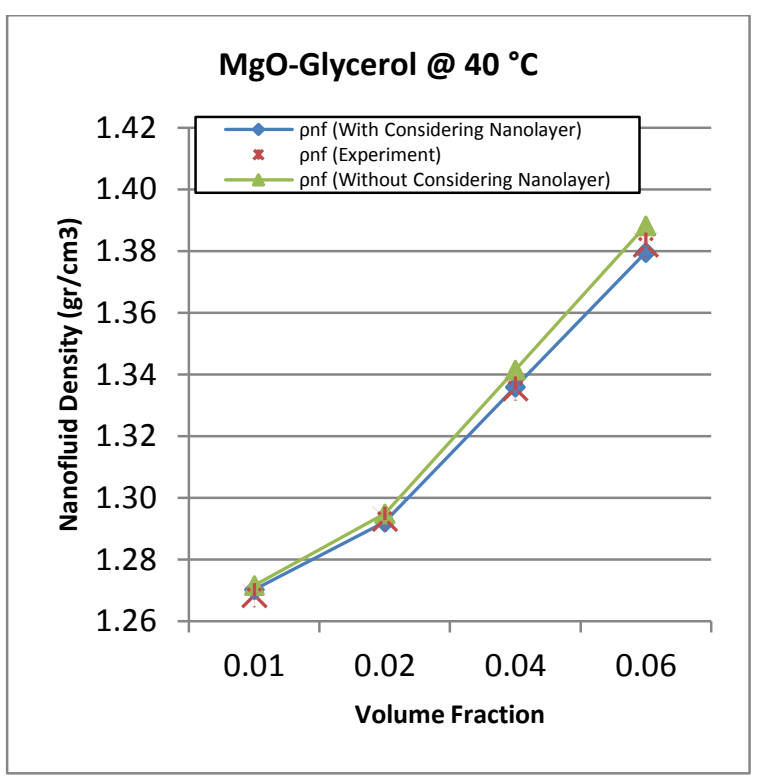

(D)

Fig. 3 


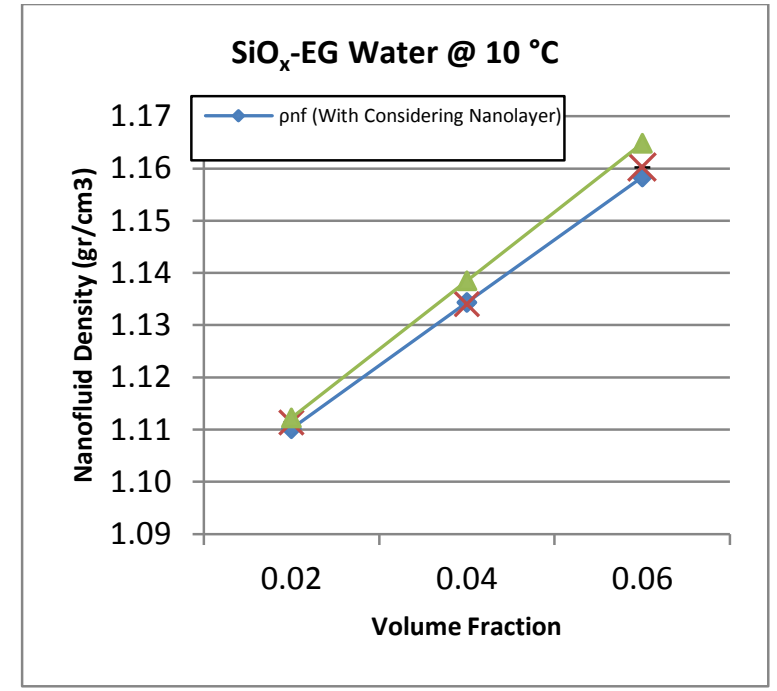

(A)

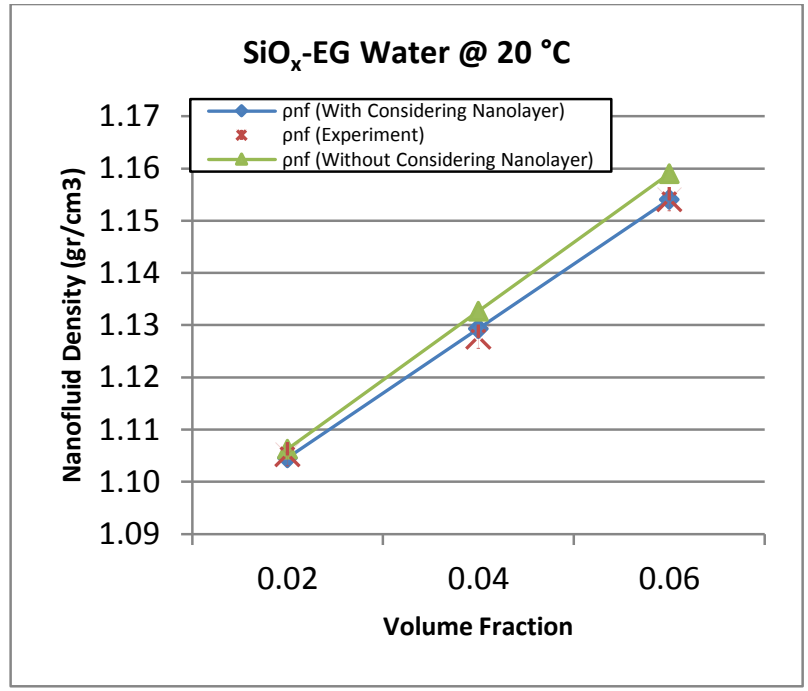

(B)

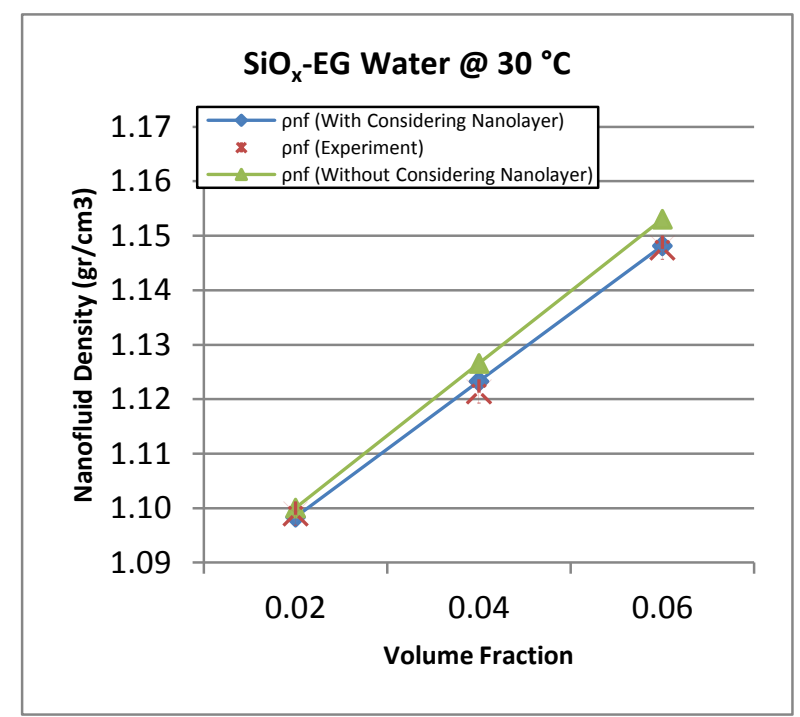

(C)

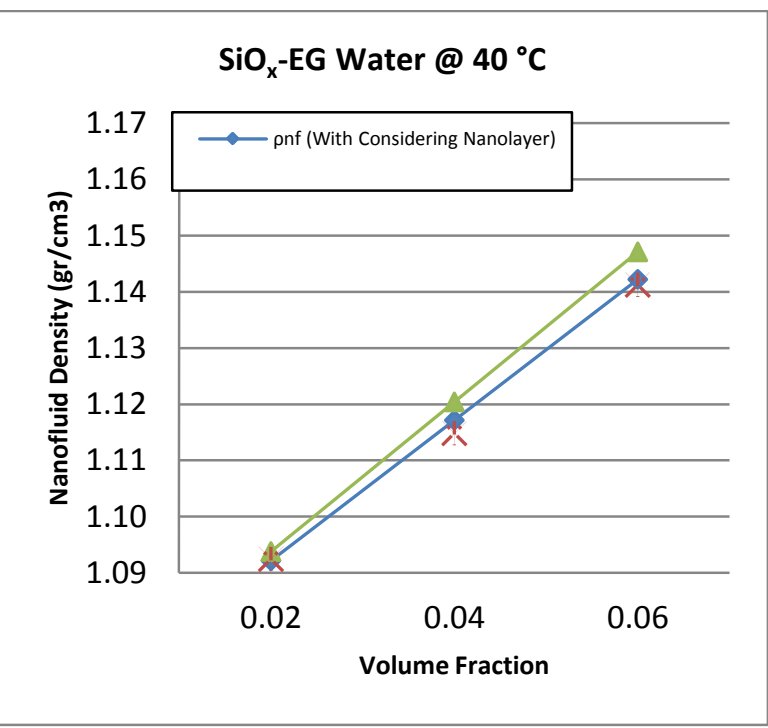

(D)

Fig. 4 